\title{
MOEDAS VIRTUAIS NO BRASIL
}

Patricia Etsuko Issonaga* Deise Marcelino da Silva*

\begin{abstract}
RESUMO
A pesquisa tem como objetivo reconhecer que as moedas virtuais são parte da inovação tecnológica, dispondo da capacidade de produzir resultados comerciais e consequentemente tributários. Aborda-se o conceito de moeda nacional e moeda virtual. Enfatiza-se a importância da ampliação do desenvolvimento humano em novas formas de tecnologia com a aplicação de inovação na economia. Através dos estudos bibliográficos verifica-se que as moedas virtuais têm por finalidade substituir o dinheiro de papel e acabar com a intermediação das operações financeiras. Neste sentido, delineia-se a problematização tributária, em virtude da ausência de legislação complementar regulamentadora específica para as moedas virtuais no Brasil.
\end{abstract}

PALAVRAS-CHAVE: Moedas Virtuais; Dinheiro; Desenvolvimento; Inovação; Tecnologia.

\section{VIRTUAL CURRENCIES IN BRAZIL}

\begin{abstract}
The research aims to recognize that virtual currencies are part of technological innovation, with ability to produce commercial and consequently, tax results. The concept of national currency and virtual currency is addressed. The importance of expanding human development in new forms of technology with the application of innovation in the economy is emphasized. Through bibliographic studies, it is verified that virtual currencies are intended to replace paper money and end the intermediation of financial transactions. In this sense, the tax problem is outlined, due to the absence of specific complementary regulatory legislation for virtual currencies in Brazil.
\end{abstract}

KEYWORDS: Virtual Currencies; Money; Development; Innovation; Technology.

\section{INTRODUÇÃO}

O Banco Central do Brasil ${ }^{1}$ conceitua moeda nacional como o meio pelo qual são efetuadas as transações monetárias em um país, ou seja, trata-se de todo ativo que constitui

* Aluna do Programa de Mestrado Profissional em Direito, Sociedade e Tecnologias da Escola de Direito das Faculdades Londrina/PR. (2020). Advogada. E-mail: patriciaissonaga@gmail.com.

*** Doutora em Direito Ambiental Internacional pela UNISANTOS (2017). Professora do Programa de Mestrado Profissional em Direito, Sociedade e Tecnologias da Escola de Direito das Faculdades Londrina/PR. E-mail: deise.marcelino@hotmail.com. 
forma imediata de solver débitos, com aceitabilidade geral e disponibilidade imediata, e que confere ao seu titular um direito de saque sobre o produto social. Com o objetivo reconhecer que as moedas virtuais são parte da inovação tecnológica, considera-se que a capacidade de tais moedas produzirem resultados comerciais e consequentemente tributários.

Moedas virtuais ${ }^{2}$ são formas não regulamentadas de dinheiro virtual, distribuída e controlada por seus desenvolvedores, usada e aceita apenas entre membros de uma comunidade virtual específica, segundo a conceituação do Banco Central Europeu ${ }^{3}$. E a utilização das criptomoedas fomenta que o paradigma de inovação tecnológica é o propício cenário para criação de novas formas de construção, produção e negociação que geram novas relações jurídicas, produção de riqueza e amplitude do conhecimento humano, modificando a cultura e a sociedade em novas formas de vida.

O BitCoin ${ }^{4}$ foi criado pelo pseudônimo Satoshi Nakamoto ${ }^{5}$ lançando o sistema operacional de moedas virtuais para transferir recursos financeiros entre pessoas, utilizando-se de tecnologia denominada blockchain ${ }^{6}$.

O sistema de pagamento global tem por objetivo substituir o dinheiro de papel e acabar com a intermediação das operações financeiras dos bancos, com menores custos de transação, sendo que a cotação não se submete às leis de nenhum governo específico.

Com o surgimento do dinheiro, a humanidade usufrui do avanço da economia para além do nível simplificado e primitivo baseado no escambo, ou seja, deixa-se de utilizar um meio de troca geral, diferenciando as mercadorias por um preço determinado.

Neste contexto, o estudo almeja demonstrar que com o avanço da ciência, tecnologia e inovação, desenvolve-se a problematização da tributação das moedas virtuais, em virtude

\footnotetext{
${ }^{1}$ Definição de Moeda Nacional disposto no site do Banco Central do Brasil (BCB). Disponível em: https://www.bcb.gov.br/content/estabilidadefinanceira/ISO_20022/SG_ISO20022-TF_Anexo_A_Glossario.pdf.

${ }^{2}$ Criptomoedas são ativos criptográficos são um novo tipo de ativo registrado em formato digital e habilitado pelo uso de criptografia. Ao contrário das notas de euro, os cripto-ativos não representam um direito financeiro ou uma responsabilidade perante qualquer entidade identificável. Derivam sua novidade e perfil de risco específico, particularmente sua alta volatilidade inerente, da ausência de um valor fundamental subjacente.

EUROPEAN BANKING AUTHORITY (EBA). Tradução do inglês Innovation in Market Infrastructure and Payments: Inovação em Infraestrutura de Mercado e Pagamentos. Disponível em: <https://www.ecb.europa.eu/paym/integration/innovation/html/index.pt.html>. Acesso em: 01. abr.2021.

${ }^{3} \mathrm{O}$ Banco Central Europeu (BCE) é o banco responsável pelo controle do EURO e sua principal função é preservar o poder de compra, assegurando a estabilidade da economia dos países da União Europeia que a utilizam como moeda nacional. EUROPEAN BANKING AUTHORITY (EBA). Opinion on 'virtual currencies', p.10. Disponível em: <https://www.ecb.europa.eu/ecb/html/index.pt.html>. Acesso em: 01 abr.2021.

${ }^{4}$ BitCoin: moeda virtual que é o resultado de décadas de pesquisa criptográfica, assinaturas digitais e variáveis.

${ }^{5}$ NAKAMOTO, Satoshi. Bitcoin: A Peer-to-Peer Eletronic Cash System. 2008. Disponível em: <https:// bitcoin.org/bitcoin.pdf>. Acesso em: 01 abr.2021.

${ }^{6}$ Tradução do inglês Blockchain: cadeia de blocos.
} 
dos fortes indícios do crescimento exponencial pelos investimentos multiplicados por criptomoedas $^{7}$ no Brasil, ainda sem legislação complementar.

\section{INOVAÇÃO TECNOLÓGICA: MOEDAS VIRTUAIS}

A internet é a espinha dorsal da comunicação global mediada por computadores. E em 1973 havia 25 computadores conectados à rede; ao longo dos anos 1970, a internet funcionava com apenas 256 computadores. No início da década de 1980, após aperfeiçoamentos significativos, ainda era restrita a cerca de 25 redes com somente algumas centenas de computadores primários e alguns milhares de usuários (CASTELLS, 2020, p.431).

A internet modificou o temo e o espaço, originando um novo meio de realização de
condutas sociais. As tecnologias da informação com base na eletrônica demonstram
uma capacidade de armazenamento de memória e velocidade de combinação e
transmissão em bits incomparáveis, gerando, então, uma relação espaço/tempo
ubíqua e assíncrona. (JANINI, 2014, p.41).

O índice de difusão da internet em 1999 se tornou muito grande no mundo inteiro, deixando claro que o acesso generalizado seria a norma nos países avançados no início do século XXI (CASTELLS, 2020, p.437).

O conhecimento necessário para gerar novas regras para um projeto, uma construção e aplicação de possibilidades técnicas instrumentais para solução de diferentes tipos de problemas, com possibilidade de substituição por novas formas, é a inovação, que rompe com a tecnologia costumeira.

A tecnologia não determina a sociedade e nem a sociedade escreve o curso da transformação tecnológica, uma vez que muitos fatores, inclusive criatividade e iniciativa empreendedora, intervêm no processo de descoberta científica, inovação tecnológica e aplicações sociais, sendo o resultado dependente de um complexo padrão interativo (CASTELLS, 2020, p.64).

Pode-se afirmar que a sociedade deste início de século é marcada por ser técnica, de massas e consumista. Torna-se imperioso reconhecer que a técnica desempenha um papel fundamental na formação do homem (LEMOS, 2020, p. 29).

\footnotetext{
${ }^{7}$ Criptomoedas: moedas virtuais que transferem recursos financeiros, utilizando-se a tecnologia blockchain.
} 
Neste sentido, a inovação tecnológica significa a capacidade de um projeto de pesquisa e desenvolvimento produzir resultados comercializáveis. A ideia de inovação tecnológica está associada a novo produto que chega ao mercado e não simplesmente ao atingimento de algum resultado técnico relevante (MAXIMIANO, 2014, p. 168).

O ser humano possui a capacidade de destruir o planeta Terra e, concomitantemente, o poder de produzir elementos não encontrados na natureza, transformação a massa em energia ou da radiação em matéria (ARENDT, 2007, p. 281), sendo um exemplo de fenômeno que traduz o nível da capacidade humana, que demonstra a sua possibilidade de criar tecnologias inovadoras.

O paradigma de inovação tecnológica é o propício cenário para criação de novas formas de construção, produção e negociação que geram novas relações jurídicas, produção de riqueza e amplitude do conhecimento humano, modificando a cultura e a sociedade em novas formas de vida (BENFATTI, 2021, p. 60).

Aproveitando novas oportunidades de inovação incentivadas pela revolução da internet, o Vale do Silício fez crescer sua liderança tecnológica em informática em relação ao resto do mundo. Mas o Vale do Silício no ano 2000 é, social e etnicamente, um Vale do Silício completamente diferente do que era na década de 1970. (CASTELLS, 2020. p. 180).

A evolução cumulativa através do meio troca no livre mercado é a única maneira que o dinheiro pode surgir e se estabelecer na sociedade. Não basta a criação de materiais inúteis ou pedaços de papel denominados "dinheiro", é imprescindível que o bem estipulado possua um histórico como meio de troca (ROTHBARD, 2013, p.16).

O Banco Central Europeu ${ }^{8}$ estabeleceu o conceito de moedas virtuais ${ }^{9}$ como forma não regulamentada de dinheiro virtual, comumente distribuída e controlada por seus desenvolvedores, usada e aceita apenas entre membros de uma comunidade virtual específica. Criptomoedas são novos meios de transferir recursos financeiros (CASTELLO, 2019, p. 3).

\footnotetext{
${ }^{8}$ Banco Central Europeu (BCE) é o banco responsável pelo controle do EURO e sua principal função é preservar o poder de compra, assegurando a estabilidade da economia dos países da União Europeia que a utilizam como moeda nacional. Disponível em: <https://www.ecb.europa.eu/ecb/html/index.pt.html>.

${ }^{9}$ Moedas Virtuais: Criptomoedas
} 
Em meados de 1985, nos primórdios da Internet, surgiram as noções de moedas virtuais e as primeiras transações virtuais ocorreram em 1994 com a DigiCash ${ }^{10}$ que faliu em 1998. Em 2005, o uso da BitGold ${ }^{11}$ permitiu a criação de impedimento da clonagem de moedas, priorizando-se a sustentabilidade do sistema com transferências imediatas, por meio do artifício denominado proof-of-work ${ }^{12}$, semelhante ao atual blockchain ${ }^{13}$ que institui a atuação dos denominados "mineradores" que validam as transações financeiras no plano teórico, sem a aplicação prática (CHAUM, 1985, p.1035).

É interessante notar que apesar do Blockchain ser comumente denominado como "a tecnologia por trás do Bitcoin", white paper do Satoshi Nakamoto em nenhum momento menciona a palavra blockchain, não obstante descreva a base de dados onde são registradas as transações como "uma rede que marca o tempo das transações, colocando-as em uma cadeia contínua no 'hash', formando um registro que não pode ser alterado sem refazer todo o trabalho". Assim, o uso do termo Blockchain veio com o tempo, não foi definido especificamente no white paper da Rede Bitcoin. (CAMPOS, 2020. p. 20).

Blockchain são pedaços de códigos gerados e conectados formando uma corrente virtual, como um sistema semelhante a um livro contábil que mantém o registro das transações, permitindo o rastreamento, o envio e o recebimento de alguns tipos de informações criptografadas ${ }^{14}$ dispensando-se a validação de intermediários (CASTELLO, 2019, p.3 e p.4).

As transações realizadas na Rede Bitcoin são processadas e registradas em um banco de dados semelhante a um livro contábil virtual, contínuo, que é o Blockchain, e que cada componente da rede possui uma cópia em seu computador, formando uma rede distribuída. Assim, no Blockchain da Rede Bitcoin é possível verificar todas as

\footnotetext{
${ }^{10}$ DigiCash: moeda virtual criada em 1994, pela empresa fundada por David Chaum, que utilizava protocolos criptográficos.

${ }^{11}$ BitGold: moeda virtual criada em 1998 por Nick Szabo, que afirmou: "Seria muito legal se houvesse um protocolo na qual bits de valor elevado pudessem ser criados on-line, de um jeito impossível de falsificar, com dependência mínima em terceiros e, então, seguramente armazenados, transferidos e verificados igualmente, com mínima necessidade de confiança". Apresentou-se como solução para todas as transações, inserindo em registro público, refletindo as propriedades do ouro. Não teve sucesso, mas inspirou outras moedas virtuais a entrarem no mercado.

${ }^{12}$ Tradução do inglês Proof-of-work: prova de trabalho.

13 Tradução do inglês Blockchain: cadeia de blocos.

14 Criptografia: Arte ou processo de escrever em caracteres secretos ou em cifras; esteganografia. Ativos criptográficos são um novo tipo de ativo registrado em formato digital e habilitado pelo uso de criptografia. Ao contrário das notas de euro, os cripto-ativos não representam um direito financeiro ou uma responsabilidade perante qualquer entidade identificável. Os cripto-ativos derivam sua novidade e perfil de risco específico, particularmente sua alta volatilidade inerente, da ausência de um valor fundamental subjacente.

EUROPEAN BANKING AUTHORITY (EBA).Tradução do inglês Innovation in Market Infrastructure and Payments: Inovação em Infraestrutura de Mercado e Pagamentos. Disponível em: <https://www.ecb.europa.eu/paym/integration/innovation/html/index.pt.html>. Acesso em: 01. abr.2021.
} 
transações já realizadas, desde a primeira em 2009, pois os registros são contínuos, públicos e rastreáveis. Nesse sentido, Bitcoin é o token nativo da Rede, enquanto Blockchain é o banco de dados onde são realizadas e registradas as transações realizadas. (CAMPOS, 2020. p. 20).

Posteriormente, surgiu o B-Money ${ }^{15}$ e outras diversas moedas virtuais, como: HashCash $^{16}$ e E-Gold ${ }^{17}$ (CHAUM, 1985, p.1038) que inspiraram o BitCoin, Ethereum, XRP, LiteCoin, EOS, Cardano, Binance Coin, Stellar Lumens, Chainlink, NEO, StableCoins, entre outras criptomoedas da atualidade ${ }^{18}$ (PIRES, 2017, p. 413).

Em 2008, o conceito do BitCoin ${ }^{19}$ criado por pessoa desconhecida, apenas denominada pelo pseudônimo Satoshi Nakamoto ${ }^{20}$ lançou o sistema operacional de moedas virtuais para transferir recursos financeiros entre pessoas. Protagonista do surgimento na utilização de tecnologia com protocolo de confiança, gera e organiza dados digitais mundiais, empoderando multidões além do mundo das finanças e na sua gestão (ARANHA, 2020, p.52).

O sistema de pagamentos global do BitCoin $^{21}$ permite a transmissão de fundos em qualquer parte do mundo, com menores custos de transação, sendo que a cotação não se submete às leis de nenhum governo específico (ULRICK, 2014, p. 23).

Criado em um cenário de crise mundial e bolha imobiliária, o bitcoin - moeda virtual que utiliza a tecnologia Blockchain - nasceu para, entre outros objetivos e usos, prevenir o chamado gasto duplo e aumentar a confianças das transações financeiras, levando-as para a internet. (CASTAGNA, 2020, p.557).

Mineradores são quaisquer pessoas que procuram usar seus próprios dispositivos para validar as transações, decodificando suas criptografias em troca da chance de receber novos códigos originais da moeda virtual, criados intrinsecamente no sistema em modo de expansão monetária, viabilizando a cobrança de taxas de baixo valor entre as respectivas transações (MARTINS; VAL, 2016, p. 230).

\footnotetext{
${ }^{15}$ B-Money: moeda virtual pioneira, proposta em 1998 por Wei Dai, com um sistema que incluía uma espécie de contrato na rede que poderia ser executado sem envolvimento de terceiros. Inspirou outras moedas virtuais a prosseguirem com proposta semelhante (Ethereum).

${ }^{16}$ HashCash: moeda virtual proposta em 1992 por Cynthia Dwork e Moni Naor para restringir o spam de emails.

${ }^{17}$ E-Gold: moeda virtual desenvolvida em 1996 por Douglas Jackson e Barry Downey, no intuito de criar um projeto inovador lastrado em ouro, mostrando o número de pessoas utilizando a moeda virtual. Alcançou o pico em 2006 e começou a apoiar outros metais preciosos. Terminou devido a questões legais

${ }_{18}$ Disponível em: https://sl.empiricus.com.br/p/crl10t-internetdescentralizada/?xpromo=XE-ME-GGL-CRL10KW-X-SH-KWINSERT-RSA\&gclid=Cj0KCQjwubHBhCyARIsAPctr7xWfznbEQnsdOEbbnkpNZuzpV3IvPxwzGSaZsKGuAz-IDj2MkkK_KcaApFtEALw_wcB.

${ }^{19}$ BitCoin: moeda virtual que é o resultado de décadas de pesquisa criptográfica, assinaturas digitais e variáveis.

${ }^{20}$ NAKAMOTO, Satoshi. Bitcoin: A Peer-to-Peer Eletronic Cash System. 2008. Disponível em: https:// bitcoin.org/bitcoin.pdf. Acesso em: 01 abr. 2021.

${ }^{21}$ BitCoin: moeda virtual que é o resultado de décadas de pesquisa criptográfica, assinaturas digitais e variáveis.
} 
Dispõem os mineradores do poder de voto proporcional à sua capacidade de processamento, com objetivo de deliberar sobre eventuais atualizações do sistema, aprimoramentos, correção de falhas e reajuste da taxa básica de transação (MARTINS; VAL, 2016, p. 231).

O caput do artigo $218^{22}$ da Constituição Federal de 1988, alterado pela redação da Emenda Constitucional $\mathrm{n}^{\mathrm{o}} 85 / 2015^{23}$ destaca que o Estado promoverá e incentivará o desenvolvimento científico, a pesquisa, a capacitação científica e tecnológica e a inovação, inspirando as atividades econômicas, portanto, neste sentido, devem nortear o desenvolvimento das moedas virtuais de modo a aprimorar o desenvolvimento econômico e tecnológico no Brasil.

A Constituição de 1988, numa verdadeira mudança paradigmática, destinou um capítulo próprio para a matéria do desenvolvimento tecnológico e científico do país, demonstrando relevância conferida à matéria, a ponto de vincular o legislador, tolhendo seu espaço de livre conformação a certas posturas e orientações mínimas. (TAVARES, 2007, p. 7).

Em consonância com o texto constitucional, a Lei $\mathrm{n}^{\mathrm{o}} 13.243 / 2016^{24}$ enumera os princípios da inovação tecnológica com objetivo de gerar o desenvolvimento econômico e social, promover incentivos à constituição de ambientes favoráveis pela inovação e às

${ }^{22}$ Constituição Federal. Artigo 218: O Estado promoverá e incentivará o desenvolvimento científico, a pesquisa, a capacitação científica e tecnológica e a inovação.

$\S 1^{\circ}$ A pesquisa científica básica e tecnológica receberá tratamento prioritário do Estado, tendo em vista o bem público e o progresso da ciência, tecnologia e inovação.

$\S 2^{\circ}$ A pesquisa tecnológica voltar-se-á preponderantemente para a solução dos problemas brasileiros e para o desenvolvimento do sistema produtivo nacional e regional.

$\S 3^{\circ} \mathrm{O}$ Estado apoiará a formação de recursos humanos nas áreas de ciência, pesquisa, tecnologia e inovação, inclusive por meio do apoio às atividades de extensão tecnológica, e concederá aos que delas se ocupem meios e condições especiais de trabalho.

$\S 4^{\circ}$ A lei apoiará e estimulará as empresas que invistam em pesquisa, criação de tecnologia adequada ao País, formação e aperfeiçoamento de seus recursos humanos e que pratiquem sistemas de remuneração que assegurem ao empregado, desvinculada do salário, participação nos ganhos econômicos resultantes da produtividade de seu trabalho.

$\S 5^{\circ}$ É facultado aos Estados e ao Distrito Federal vincular parcela de sua receita orçamentária a entidades públicas de fomento ao ensino e à pesquisa científica e tecnológica.

$\S 6^{\circ} \mathrm{O}$ Estado, na execução das atividades previstas no caput, estimulará a articulação entre entes, tanto públicos quanto privados, nas diversas esferas de governo.

$\S 7^{\circ} \mathrm{O}$ Estado promoverá e incentivará a atuação no exterior das instituições públicas de ciência, tecnologia e inovação, com vistas à execução das atividades previstas no caput.
23
Emenda
Constitucional
$\mathrm{n}^{\mathrm{o}}$
$85 / 2015$.
Disponível
em:

http://www.planalto.gov.br/ccivil_03/constituicao/emendas/emc/emc85.htm.

${ }^{24}$ Lei $n^{\circ} 13.243 / 2016$, dispõe sobre estímulos ao desenvolvimento científico, pesquisa, capacitação científica, tecnológica e à inovação. Disponível em: http://www.planalto.gov.br/ccivil_03/_ato20152018/2016/lei/113243.htm. 
atividades de transferência de tecnologia, de modo a fortalecer o Sistema Nacional de Ciência, Tecnologia e Inovação (SNCTI), especialmente a partir da Emenda Constitucional $\mathrm{n}^{\circ}$ $85 / 2015$.

Os investimentos feitos em Ciência, Tecnologia e Informação trazem retornos na forma de uma população mais bem qualificada, de empregos mais bem remunerados, de geração de divisas e de melhor qualidade de vida (SILVA; MELO, 2001, p. 14).

\begin{abstract}
O sistema financeiro global movimenta trilhões de dólares diariamente, servindo a bilhões de pessoas e apoiando uma economia global de mais de 100 trilhões de dólares. É a indústria mais poderosa do mundo, a fundação do capitalismo global, e seus líderes são conhecidos como os Mestres do Universo. [...] Inovação de valor: o Blockchain do Bitcoin foi projetado para mover Bitcoins, não para lidar com outros ativos financeiros. No entanto, a tecnolocia é de código aberto, convidando à experimentação (TAPSCOTT, 2016, p.89 e p.94).
\end{abstract}

No contexto da ciência, tecnologia e inovação, aborda-se o problema da tributação das moedas virtuais, pois com os fortes indícios do crescimento exponencial pelos investimentos multiplicados por criptomoedas ${ }^{25}$ (CASTAGNA, 2020, p.562), consolidados com os avanços tecnológicos e disponibilizados na internet, torna-se necessária a aplicação de legislação específica.

\title{
3 A PROBLEMÁTICA DAS MOEDAS VIRTUAIS NO BRASIL
}

O Banco Central do Brasil ${ }^{26}$ conceitua moeda nacional como o meio pelo qual são efetuadas as transações monetárias em um país, ou seja, trata-se de todo ativo que constitui forma imediata de solver débitos, com aceitabilidade geral e disponibilidade imediata, e que confere ao seu titular um direito de saque sobre o produto social.

A moeda possui grande importância na economia, pois geram o meio geral de troca, reserva de valor e unidade de conta. Neste aspecto, o Real como moeda corrente brasileira,

\footnotetext{
${ }^{25}$ Criptomoedas: sinônimo de moedas virtuais que transferem recursos financeiros, utilizando-se a tecnologia blockchain.

${ }^{26}$ Definição de Moeda Nacional disposto no site do Banco Central do Brasil (BCB). Disponível em: https://www.bcb.gov.br/content/estabilidadefinanceira/ISO_20022/SG_ISO20022-TF_Anexo_A_Glossario.pdf.
} 
tendo por curso legal nacional desde $1^{\circ}$ de julho de 1994, a unidade do Sistema Monetário Nacional, nos termos da Lei $n^{\circ} 9.069 / 1995^{27}$.

O termo moeda refere-se a ativos que as pessoas usam regularmente para comprar bens e serviços. A moeda tem três funções. Como meio de troca, é o item usado para realizar transações. Como unidade de conta, proporciona uma maneira pela qual preços e outros valores econômicos são registrados. Como reserva de valor, proporciona uma maneira de transferir poder de compra do presente para o futuro. (MANKIW, 2021, p.500).

Para a legislação brasileira são nulas as convenções de pagamento em ouro ou em moeda estrangeira, assim como a compensação da diferença com moeda nacional, excetuados os casos previstos na legislação especial, como também, as dívidas em dinheiro que devem ser adimplidas sempre em moeda corrente, dispostos na Lei $n^{\circ} 10.406 / 2002^{28}$.

Toda e qualquer demanda por dinheiro é utilizada para calcular preços. Assim como há grande variedade de habilidades e recursos na natureza, existe uma grande variedade na comerciabilidade dos bens existentes que são utilizados como meio gerais de troca. (ROTHBARD, 2013, p.15).

[...] a evolução cumulativa de um meio de troca no livre mercado - é a única maneira pela qual o dinheiro pode surgir e ser estabelecido. $\mathrm{O}$ dinheiro não pode se originar de nenhuma outra maneira: mesmo que as pessoas repentinamente decidam criar dinheiro utilizando materiais inúteis, ou o governo decrete que determinados pedaços de papel agora são "dinheiro", nada disso pode funcionar se o bem estipulado não possuir um histórico como meio de troca. (ROTHBARD, 2013, p.16).

\footnotetext{
${ }^{27}$ Lei $\mathrm{n}^{\circ} 9.069 / 1995$, artigo $1^{\circ}$ : A partir de $1^{\circ}$ de julho de 1994, a unidade do Sistema Monetário Nacional passa a ser o REAL (Art. $2^{\circ}$ da Lei $\mathrm{n}^{\circ}$ 8.880, de 27 de maio de 1994), que terá curso legal em todo o território nacional. $\S 1^{\circ}$ As importâncias em dinheiro serão grafadas precedidas do símbolo $\mathrm{R} \$$.

$\S 2^{\circ}$ A centésima parte do REAL, denominada "centavo", será escrita sob a forma decimal, precedida da vírgula que segue a unidade.

$\S 3^{\circ}$ A paridade entre o REAL e o Cruzeiro Real, a partir de $1^{\circ}$ de julho de 1994 , será igual à paridade entre a Unidade Real de Valor - URV e o Cruzeiro Real fixada pelo Banco Central do Brasil para o dia 30 de junho de 1994.

$\S 4^{\circ}$ A paridade de que trata o parágrafo anterior permanecerá fixa para os fins previstos no art. $3^{\circ}$, $3^{\circ}$, da Lei ${ }^{\circ}$ 8.880 , de 27 de maio de 1994, e no art. $2^{\circ}$ desta Lei.

$\S 5^{\circ}$ Admitir-se-á fracionamento especial da unidade monetária nos mercados de valores mobiliários e de títulos da dívida pública, na cotação de moedas estrangeiras, na Unidade Fiscal de Referência - UFIR e na determinação da expressão monetária de outros valores que necessitem da avaliação de grandezas inferiores ao centavo, sendo as frações resultantes desprezadas ao final dos cálculos.

${ }^{28}$ Lei $^{\circ}{ }^{10.406 / 2002}$ : Art. 315. As dívidas em dinheiro deverão ser pagas no vencimento, em moeda corrente e pelo valor nominal, salvo o disposto nos artigos subsequentes; Art. 318: São nulas as convenções de pagamento em ouro ou em moeda estrangeira, bem como para compensar a diferença entre o valor desta e o da moeda nacional, excetuados os casos previstos na legislação especial.
} 
Em geral, quanto às moedas virtuais (ou criptomoedas) não há obrigatoriedade de aceitação por parte de nenhuma comunidade, assim como não existe a fixação de moeda corrente e nenhum curso forçado e o seu poder liberatório decorre de quem as recebe. Apesar de não serem regulamentadas pelo Banco Central do Brasil as moedas virtuais têm sido comumente utilizadas como meio de poupança e aplicação financeira, assim como forma de pagamento entre os integrantes da comunidade virtual (CASTELLO, 2019, p.6).

Com o surgimento e evolução dos computadores e da internet, as obrigações acometidas ao contribuinte, abandonaram o papel como suporte físico e passaram a ser elaboradas eletronicamente. A produção das obrigações acessórias tributárias deve ser considerada inerente aos Direitos Fundamentais do Contribuinte (JANINI, 2014, p.292).

\begin{abstract}
O século XX ficou marcado pelas céleres transformações que propiciou, em todas as áreas, acarretando mudanças no modo de condução da economia, da cultura, das interações sociais, do trabalho, da pesquisa científica e, naturalmente, do Direito. A humanidade, em poucos anos, se viu inserida em um contexto de acelerado desenvolvimento tecnológico, catalisado pelo clamor da inovação em décadas marcadas por disputas bélicas e suas nefastas consequências, grandes expectativas quanto às invenções e descobertas, e também por uma busca incessante de otimização das rotinas, aumento de produtividade e de melhoria do conforto da população em geral" (FALEIROS JÚNIOR, 2021, p. 56).
\end{abstract}

Dispostos no artigo $5^{\circ}$ e artigo 150 da Constituição Federal (BRASIL, 1988), o princípio da legalidade, princípio da anterioridade, princípio do não-confisco, princípio da inviolabilidade do domicílio fiscal, princípio da liberdade de exercício de atividade econômica e princípio da livre iniciativa, constituem por deveres fundamentais que são imposições constitucionais aos particulares, tais como o dever de pagar tributos (JANINI, 2014, p. 301).

A revolução digital estimula o direito. Neste cenário, o direito precisa se movimentar com o intuito de normatizar as condutas virtuais, cibernéticas ou digitais. Os comportamentos humanos realizados no ciberespaço igualmente têm de ser regulamentados pelo sistema jurídico. (JANINI, 2014, p.287).

Com o desenvolvimento da ciência, tecnologia e inovação torna-se evidente a problematização da tributação das moedas virtuais no Brasil, diante da ausência de legislação complementar. Neste aspecto, na tributação de operação de compra e venda de criptomoedas 
aplica-se os termos do Código Tributário Nacional, disposto na Lei $\mathrm{n}^{\circ} 5.172 / 1966^{29}$ e suas legislações correlatas (CASTAGNA, 2020, p.583).

\begin{abstract}
Virtual Currencies are a digital representation of value that is neither issued by a central bank or a public authority, nor necessarily attached to a FC, but is accepted by natural or legal persons as a means of payment and can be transferred, stored or traded electronically. The main actors are users, exchanges, trade platforms, inventors, and e-wallet providers ${ }^{30}$ (WILLIAMS, 2014, p.5).
\end{abstract}

Por analogia, nas operações de câmbio são aplicáveis às moedas virtuais, a qual devem ser declaradas no imposto de renda, apura-se o eventual ganho de capital, especificados como Bens e Direitos (CASTELLO, 2019, p.16).

A questão é que, em um mercado genuinamente livre, o ouro simplesmente seria transacionado diretamente em gramas, grão ou onças, e tais denominações confusas, como dólares, francos, marcos, etc., seriam supérfluas. [...] É certo que o livre mercado irá escolher como sendo a unidade comum aquela grandeza do dinheiromercadoria que for a mais conveniente. (ROTHBARD, 2013, p.21).

De modo geral, quando as políticas públicas do governo são formuladas, a eficiência e a igualdade entram em conflito. Ao redistribuir as rendas dos ricos para os pobres, há redução da recompensa pelo trabalho árduo, consequentemente as pessoas trabalham menos e produzem menos bens e serviços. Neste sentido, as moedas virtuais são tradeoffs ${ }^{31}$, ou seja, são parte da tomada de decisões, exigindo-se a escolha de um objetivo em detrimento de outro (MANKIW, 2021, p.3).

Com o crescimento dos impostos, os incentivos se tornam cada vez mais distorcidos, e o peso morto, cada vez maior. Entretanto, como um imposto reduz o tamanho do mercado, a receita tributária não aumenta continuamente. Primeiro ela cresce com o tamanho do imposto, mas se esse imposto aumentar muito, ela começará a diminuir. (MANKIW, 2021, p.135).

${ }^{29}$ Lei ${ }^{\circ}$ 5.172/1966. Código Tributário Nacional. Sistema Tributário Nacional que institui normas gerais de Direito Tributário aplicáveis à União, Estados e Municípios. Disponível em: http://www.planalto.gov.br/ccivil_03/leis/15172compilado.htm.

30 Tradução do inglês: Moedas virtuais são uma representação digital de valor que não é emitida por um banco central ou autoridade pública, nem necessariamente vinculada a uma FC, mas é aceita por pessoas físicas ou jurídicas como meio de pagamento e pode ser transferida, armazenada ou comercializados eletronicamente. Os principais atores são usuários, bolsas, plataformas de comércio, inventores e fornecedores de carteiras eletrônicas.

${ }^{31}$ Em economia, tradeoff é um tempo que define uma situação de escolha conflitante, isto é, quando uma ação econômica que visa à resolução de determinado problema acarreta, inevitavelmente, outros. 
Os Direitos Fundamentais do Contribuinte em relação às moedas virtuais não são barreiras intransponíveis para a instituição e nem mera exigência dos deveres instrumentais eletrônicos, todavia, atuam como parâmetro jurídico a fim de evitar abusivas e injustas obrigações exigidas pela Administração Tributária (JANINI, 2014, p. 305).

\section{CONCLUSÕES}

A inovação tecnológica significa a capacidade de um projeto de pesquisa e desenvolvimento produzir resultados comercializáveis. A ideia de inovação tecnológica está associada a novo produto que chega ao mercado e não simplesmente ao atingimento de algum resultado técnico relevante.

Segundo o Banco Central do Brasil, moeda é o meio pelo qual são efetuadas as transações monetárias em um país, ou seja, trata-se de todo ativo que constitui forma imediata de solver débitos, com aceitabilidade geral e disponibilidade imediata, e que confere ao seu titular um direito de saque sobre o produto social.

A moeda possui grande importância na economia, pois geram o meio geral de troca, reserva de valor e unidade de conta. Para a legislação brasileira são nulas as convenções de pagamento em ouro ou em moeda estrangeira, assim como a compensação da diferença com moeda nacional, excetuados os casos previstos na legislação especial.

O Banco Central Europeu conceitua que moeda virtual é a forma não regulamentada de dinheiro virtual, comumente distribuída e controlada por seus desenvolvedores, usada e aceita apenas entre membros de uma comunidade virtual específica.

As criptomoedas são ativos criptográficos, ou seja, um novo tipo de ativo registrado em formato digital e habilitado pelo uso de criptografia. Ao contrário das notas de euro, as criptomoedas não representam um direito financeiro ou uma responsabilidade perante qualquer entidade identificável. Derivam sua novidade e perfil de risco específico na sua alta volatilidade inerente, da ausência de um valor fundamental subjacente.

A DigiCash, BitGold, B-Money, HashCash e E-Gold inspiraram o BitCoin, Ethereum, XRP, LiteCoin, EOS, Cardano, Binance Coin, Stellar Lumens, Chainlink, NEO, StableCoins, entre outras criptomoedas da atualidade, que tem por objetivo substituir o 
dinheiro de papel e acabar com a intermediação das operações financeiras dos bancos, sendo que a cotação não se submete às leis de nenhum governo específico.

Com o surgimento e evolução dos computadores e da internet, as obrigações acometidas ao contribuinte, abandonaram o papel como suporte físico e passaram a ser elaboradas eletronicamente.

Diante do desenvolvimento da ciência, tecnologia e inovação torna-se evidente que a tributação das moedas virtuais serve como parâmetro jurídico, a fim de evitar abusivas e injustas obrigações exigidas pela Administração Tributária, mesmo diante da problematização e ausência de legislação complementar que regulamente as criptomoedas no Brasil.

\section{REFERENCIAS}

ARANHA, Christian. Bitcoin, Blockchain e Muito Dinheiro: uma nova chance para o mundo. $2^{a}$ Edição. Rio de Janeiro: Valentina, 2020.

ARENDT, Hannah. A Condição Humana. Tradução de Roberto Raposo. 10ª Edição. Rio de Janeiro: Forense Universitária, 2007.

BANCO CENTRAL DO BRASIL (BCB). Moeda Nacional. Disponível em: https://www.bcb.gov.br/content/estabilidadefinanceira/ISO_20022/SG_ISO20022-

TF_Anexo_A_Glossario.pdf. Acesso em: 01 abr.2021.

BANCO CENTRAL EUROPEU (BCE). Moedas Virtuais. Disponível em: https://www.ecb.europa.eu/ecb/html/index.pt.html. Acesso em: 01 abr. 2021.

BENFATTI, Fabio Fernandes Neves. Direito à Inovação. Curitiba: Editora CRV, 2021.

BRASIL. Constituição da República Federativa do Brasil (1988). Disponível em: http://www.planalto.gov.br/ccivil_03/constituicao/constituicao.htm. Acesso em: 01 abr. 2021.

BRASIL. Emenda Constitucional $\mathbf{n}^{\mathbf{0}} \mathbf{8 5} / \mathbf{2 0 1 5}$. Altera e adiciona dispositivos na Constituição Federal para atualizar o tratamento das atividades de ciência, tecnologia e inovação. Disponível em: http://www.planalto.gov.br/ccivil_03/constituicao/emendas/emc/emc85.htm. Acesso em: 01 abr.2021.

BRASIL. Lei $\mathbf{n}^{\mathbf{0}}$ 5.172/1966. Código Tributário Nacional. Dispõe sobre o Sistema Tributário Nacional que institui normas gerais de Direito Tributário aplicáveis à União, Estados e Municípios. Disponível em: http://www.planalto.gov.br/ccivil_03/leis/15172compilado.htm. Acesso em: 01 abr.2021. 
BRASIL. Lei no 9.069/1995. Dispõe sobre o Plano Real, o Sistema Monetário Nacional, estabelecendo regras e condições de emissão da cédula brasileira e os critérios para conversão das obrigações para o Real. Disponível em: http://www.planalto.gov.br/ccivil_03/leis/19069.htm. Acesso em: 01 abr.2021.

BRASIL. Lei $\mathbf{n}^{\mathbf{0}} \mathbf{1 3 . 2 4 3 / 2 0 1 6}$. Dispõe sobre os estímulos ao desenvolvimento científico, à pesquisa, à capacitação científica e tecnológica e à inovação. Disponível em: http://www.planalto.gov.br/ccivil_03/_ato2015-2018/2016/lei/113243.htm. Acesso em: 01 abr.2021.

CAMBRIGDE DICTIONARY. Dicionário. Tradução do inglês para o português. Disponível em: https://dictionary.cambridge.org/pt/dicionario/ingles-portugues/. Acesso em: 01 abr.2021.

CAMPOS, Emília Malgueiro. Criptomoedas e Blockchain: o direito no mundo digital. $2^{\mathrm{a}}$ Edição. Rio de Janeiro: Lumen juris, 2020.

CASTAGNA, Ricardo Alessandro. Blockchain e Operações Financeiras: impactos na tributação. Coordenadores: Maria Isabel Carvalho Sica Longhi [et.al.]. Direito e Novas Tecnologias. São Paulo: Almedina, 2020. p.555-589.

CASTELLO, Melissa Guimarães. Bitcoin é moeda? Classificação das Criptomoedas para o Direito Tributário. Revista Direito Getúlio Vargas (GV). V.15, $\mathrm{n}^{\circ} 3$, p. 1 a p. 20. Junho 2019.

CASTELLS, Manuel. A Sociedade em Rede. Edição Revista e Atualizada. Tradução: Roneide Venancio Majer. Prefácio: Fernando Henrique Cardoso. Vol.1.São Paulo: Paz \& Terra, 2020.

EBA, European Banking Authority. EBA Opinion on "virtual currencies". EBA/OP/2014/08. 4.Jul.2014. Disponível em: <https://www.ecb.europa.eu/ecb/html/index.pt.html>. Acesso em: 01 abr.2021.

EBA, European Banking Authority. Estudos e Publicações. "Innovation in Market Infrastructure and Payments". Disponível em: <https://www.ecb.europa.eu/paym/integration/innovation/html/index.pt.html>. Acesso em: 01 abr.2021.

FALEIROS JÚNIOR, José Luiz de Moura. A Evolução da Inteligência Artificial em Breve Retrospectiva. In: Direito Digital e Inteligência Artificial: diálogos entre Brasil e Europa. Mafalda Miranda Barbosa, Felipe Braga Netto, Michael César Silva e José Luiz de Moura Faleiros Júnior. Indaiatuba, SP: Foco, 2021, p. 56.

FERREIRA, Aurélio Buarque de Holanda. Dicionário Aurélio da Língua Portuguesa. Minimalista. Tecnologia. 5a Edição. Curitiba: Positivo, 2010.

JANINI, Tiago Cappi. Direito Tributário Eletrônico: SPED e os Direitos Fundamentais do Contribuinte. Curitiba: Juruá, 2014. 
LEMOS, André. Cibercultura: tecnologia e vida social na cultura contemporânea. 8. ed. Porto Alegre: Sulina, 2020.

MANKIW, N. Gregory. Introdução à Economia. Tradução da $8^{\text {a }}$ Edição norte-americana. Harvard University. Tradução: Priscilla Rodrigues da Silva Lopes. Revisão Técnica: Manuel José Nunes Pinto. São Paulo: Cengage, 2021.

MARTINS, Armando Nogueira da Gama Lamela; VAL, Eduardo Manuel. Criptomoedas: Apontamentos sobre seu Funcionamento e Perspectivas Institucionais no Brasil e Mercosul. Revista de Direito Internacional Econômico e Tributário (RDIET). Brasília, V.11, no 1, p. 227 a p. 252. Junho, 2016.

MAXIMIANO, Antonio Cesar Amaru. Administração de Projetos: Como transformar ideias

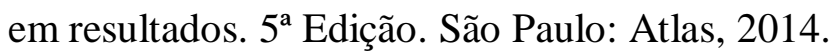

NAKAMOTO, Satoshi. Bitcoin: A Peer-to-Peer Eletronic Cash System. 2008. Disponível em: https:// bitcoin.org/bitcoin.pdf. Acesso em: 01 abr.2021.

PIRES, Hindenburgo Francisco. Bitcoin: A Moeda do Ciberespaço. GEOUSP - Espaço e Tempo (Online), b.21. $\mathrm{n}^{\mathrm{o}}$ 2, p. 407 a p. 424. Agosto, 2017. Disponível em: https://doi.org/10.11606/issn.2179-0892.geousp.2017.134538. Acesso em: Acesso em: 01 abr.2021.

ROTHBARD, Murray N. O que governo fez com o nosso dinheiro? Tradução de Leandro Augusto Gomes Roque. 1a Edição. São Paulo: Instituto Ludwig von Mises Brasil, 2013.

SILVA, Cylon Gonçalves da; MELO, Lúcia Carvalho Pinto de. Ciência, Tecnologia e Informação: desafio para a sociedade brasileira. Brasília: Ministério da Ciência e Tecnologia. Academia Brasileira de Ciências, 2001.

TAPSCOTT, Alex; TAPSCOTT, Don. Blockchain Revolution. Como a tecnologia por trás do Bitcoin está mudando o dinheiro, os negócios e o mundo. São Paulo: SENAI-SP Editora, 2016.

TAVARES, André Ramos. Ciência e Tecnologia na Constituição. In: Revista de Informação Legislativa. Brasília: Senado Federal, a. 44, nº 175, p. 7 a p. 20. Setembro, 2007.

ULRICK, Fernando. Bitcoin: a moeda na era digital. 1a Edição. São Paulo: LMV Editora, 2014.

WILLIAMS, Mark T. Virtual Currencies: bitcoin risk. Word Bank Conference. Washington: Boston University, 2014. 